\title{
Electrophysiological and behavioral responses of pea weevil Bruchus pisorum L. (Coleoptera: Bruchidae) to volatiles collected from its host Pisum sativum L.
}

\author{
Ricardo Ceballos ${ }^{1 *}$, Natalí Fernández ${ }^{1}$, Sharon Zúñiga ${ }^{2}$, and Nelson Zapata ${ }^{2}$
}

The pea weevil (Bruchus pisorum L.) (Coleoptera: Bruchidae) is one of the most damaging pests of pea (Pisum sativum L.) We investigated the role of pea volatiles on the electrophysiological and behavioral response of B. pisorum using electroantennography (EAG) and olfactometry bioassays. Plant volatiles emitted at different phenological stages were collected in situ by headspace on Porapak Q traps and analyzed through gas chromatography coupled to mass spectrometry (GC-MS). Most abundant volatiles identified in all phenological stages were terpenes and green leaf volatiles. All tested volatile extracts elicited significant EAG responses in both male and female $B$. pisorum, with females exhibiting a greater response $(1.35 \mathrm{mV})$ than males $(1.02 \mathrm{mV})$ to pea-pod volatiles. Volatiles from each phenological stage stimulated an attractant behavioral response of both males and females $B$. pisorum in olfactometer bioassay. A larger attraction of $B$. pisorum females was observed to volatiles from pods over other phenological stages $(P<0.001)$. These results suggest the relative importance of volatiles cues from plant mediating host location by $B$. pisorum. This work showed that plant volatiles elicited electrophysiological and behavioral responses and that $B$. pisorum female can discern between phenological stages of $P$. sativum based on those chemical cues.

Key words: Bruchids, EAG, IPM, pest monitoring, plant volatiles.

\section{INTRODUCTION}

Plants synthesize hundreds of metabolites; some of them are volatiles that confer a characteristic blend of odor to the plants. These volatile organic compounds released by plants can act as semiochemicals playing an important role in enabling insects to recognize host plants from a distance (Holopainen, 2004; Bruce et al., 2005; Bleeker et al., 2009). Find and selecting a host plant is crucial for a phytophagous insect to fulfill its nutritional requirements and to find suitable oviposition sites (Bruce et al., 2005). However, the plant volatiles emission is known to vary depending on both internal and external factors. Besides the climatic and geographic factors, high phenological variation in volatiles emission occurs (Casado et al., 2006; Dudareva et al., 2006) and compounds have different systematic distributions (Kundsen et al., 1993). The perception of these compounds by insects depends on its olfactory receptor neurons, mostly in the antennalsensillae (Sato and Touhara, 2009; Carey and Carlson, 2011; Hansson and Stensmyr, 2011). The perception

${ }^{1}$ Instituto de Investigaciones Agropecuarias, INIA Quilamapu, Av. Vicente Méndez 515, Chillán, Chile.

*Corresponding author (rceballos@inia.cl).

${ }^{2}$ Universidad de Concepción, Facultad de Agronomía, Av. Vicente Méndez 595, Chillán, Chile.

Received: 4 August 2014.

Accepted: 20 January 2015.

doi:10.4067/S0718-58392015000200009 of blends of plant volatiles plays a pivotal role in host recognition, non-host avoidance and ensuing behavioral responses as different responses can occur to a whole blend compared to individual components (Bruce and Pickett, 2011).

The pea weevil, Bruchus pisorum L. (Coleoptera: Bruchidae), is a cosmopolitan and most destructive insect pest of the pea (Pisum sativum L.) cultivars (Hardie and Clement, 2001; Clement et al., 2009). This strictly monophagous pest completes its univoltine life cycle only on P. sativum. The larvae, once hatched, burrow through the pod wall into maturing seeds to consuming them and complete its development, resulting in loss of yield and quality of pea crops (Clement, 1992; Michael et al., 1993). Emerging males after winter hibernation are sexually mature, but females must feed on pollen before they can lay eggs only on green pea pods (Clement, 1992; Hardie and Clement, 2001). Adults emerge from seed leaving an exit hole about 2-3 $\mathrm{mm}$, this behavior cause a direct damage by consumption of the seed and reduction of its capacity of germination, and infestations levels reported worldwide ranging from $10 \%$ to $90 \%$ (Pesho et al., 1977; Gerding et al., 1987; Horne and Bailey, 1991). This newly emerged weevil seeks sheltered sites to spend the winter and remain there until the following spring (Hardie et al., 1995).

Evidences about nature and identity of stimuli used in host finding by $B$. pisorum are scarce. Annis and O'Keeffe (1987) indicate that the monophagy of B.pisorum may be due to the response of adult females to deterrents. Pajni 
(1986) suggested that host specificity in bruchids that affects crops in field, including B. pisorum, is determined by the obligatory feeding of the adults on the pollen and nectar of their hosts for the maturation of the gonads and subsequent initiation of copulation and oviposition. Other bruchids pests of legumes respond to its host volatiles, Vicia faba (L.) flower-volatiles were electrophysiological active on the antennae of B. rufimanus (Bruce et al., 2011). Callosobruchus maculatus F. (Coleoptera: Bruchidae) in an electroantennogram experiment showed a dose-dependent response to a dichloromethane extract of its host-plant Vigna unguiculata (L.) Walp., the extract stimulated both males and females but females showed a greater response than males (Adhikari et al., 2002). In the same study authors find a similar dosedependent response of $C$. maculatus in an olfactometer bioassay. Non-host volatiles, neem (Azadirachta indica A. Juss.) elicited a repellent behavior on $C$. maculatus in olfactometer indicating the suitability of neem leafvolatiles as botanical repellent in the control of this pest (Paranagama et al., 2003).

There are not experimental evidences of chemical cues used by $B$. pisorum in host finding. In the present study we investigate the activity of the odor extracts from different phenological stages of $P$. sativum on the antennal response of $B$. pisorum. In olfactometric bioassay our objective was evaluate the attraction of odor extracts on both males and females of B. pisorum. We were able to identify volatiles from $P$. sativum that act as chemical cues eliciting an attractant behavior of the pest and obtain an initial approach to elucidate the role of pea volatile in host finding by $B$. pisorum.

\section{MATERIAL AND METHODS}

\section{Male and female $B$. pisorum}

Adults were collected from infested pea seeds harvested on an experimental pea stand at Instituto de Investigaciones Agropecuarias INIA, Chillán, Chile, between September 2009 and February 2010. Once transferred to the laboratory, male and female adults emerging from peas were maintained separately at $5{ }^{\circ} \mathrm{C}$ in plastic boxes. One hour before each behavioral assay, $B$. pisorum adults were observed for $30 \mathrm{~min}$, and those that were active in that time were selected for the experiments.

\section{Collection of volatiles from host plant}

Headspace collection of naturally released plant volatiles were made in the experimental pea stand at INIA, Chillán, for a $24 \mathrm{~h}$ period (at $1 \mathrm{~L} \mathrm{~min}^{-1}$ ) by enclosing aerial part of an individual plant of $P$. sativum 'Ambassador' $(15-30 \mathrm{~cm}$ tall) in a $900 \mathrm{~mL}$ Pyrex glass chamber $(6 \mathrm{~cm}$ ID and $30 \mathrm{~cm}$ high). Depending of the phenological stage, the aerial part of each plant included leaves, flowers, and pods. Volatiles were absorbed on $100 \mathrm{mg}$ Porapak Q columns (80-100 mesh, Waters Associates, Milford, Massachusetts, USA), previously cleaned with $1 \mathrm{~mL}$ of redistilled diethyl ether (Chromatographic grade; Merck, Darmstadt, Germany), and conditioned at $150{ }^{\circ} \mathrm{C}$ for $2 \mathrm{~h}$ in a stream of nitrogen at $70 \mathrm{~mL} \mathrm{~min} \mathrm{~m}^{-1}$. The entrainment was performed by using a positive/negative pressure air system (Agelopoulos et al., 1999). The air was dried and purified by passage through activated 5- $\AA$ molecular sieves and then charcoal, and finally drawn through glass chamber. Volatiles were extracted from the Porapak $\mathrm{Q}$ by elution with $1 \mathrm{~mL}$ of redistilled hexane (Chromatographic grade, Optima Scientific, USA) which was then concentrated to $100 \mu \mathrm{L}$ under a gently flow of nitrogen. Odor sources included three phenological stages of pea: vegetative, flowering period, and pod formation.

Identification and semi-quantification of plant volatiles An aliquot $(1.0 \mu \mathrm{L})$ of the volatile extracts was analyzed using a gas chromatograph coupled to a mass spectrometer (GCMS QP2010 Plus; Shimadzu, Tokyo, Japan) equipped with a Restek capillary column (Rxi-5ms: 5\% diphenyl-95\% dimethylpolysiloxane; $30 \mathrm{~m} \times 0.25 \mathrm{~mm}$ ID $\times 1.0 \mu \mathrm{m}$; Restek Corporation, Bellefonte, Pennsylvania USA). Helium gas was used as the gas carrier; with a

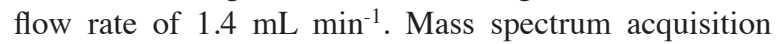
was performed in the mass range from 35 to $500 \mathrm{~m} / \mathrm{z}$. The ionization was performed by electron impact at $70 \mathrm{eV}$ with an ion source at $200{ }^{\circ} \mathrm{C}$. The GC oven was programmed to remain at $40{ }^{\circ} \mathrm{C}$ for $5 \mathrm{~min}$ and increase at $5{ }^{\circ} \mathrm{C} \mathrm{min} \mathrm{m}^{-1}$ to $230^{\circ} \mathrm{C}$ and held for $10 \mathrm{~min}$. The interface temperature was programmed at $250{ }^{\circ} \mathrm{C}$. The volatiles collected were identified by comparing gas-liquid chromatography (GLC) Kovats indices (KIs) and mass spectra (MS) with the corresponding commercial standards (Sigma Aldrich, St. Louis, Missouri, USA) and library database spectra using the National Institute of Standards and Technology (NIST) mass spectral search program (version 2.0; Standard Reference Data, NIST, Gaithersburg, Maryland, USA), and the experimental KIs were compared with theoretical KIs from synthetic standards compounds and reported in the Pherobase (El-Sayed, 2014) and NIST webbook (NIST, 2014). Calibration curves based on peak area ratio were constructed using standards for quantification of each volatile compound identified from the samples of $P$. sativum.

\section{Electrophysiological recognition and behavioral bioassay of plant volatiles}

Olfactory sensitivity of $B$. pisorum to volatile compounds from its host $P$. sativum was studied with electroantennographic (EAG) recordings, the apparatus and general procedures are described in Palma et al. (2012). For each recording, a glass pipette $\mathrm{Ag} /$ $\mathrm{AgCl}$ reference electrode (containing $\mathrm{KCl}$ and $0.1 \%$ polyvinylpyrrolidone) was inserted into the foramen of a weevil's excised head. The tip of a similar recording electrode was cut to match the diameter of the tip of 
antenna, and positioned in air stream receiving effluent from the EAG apparatus. The analog signal was detected through a probe (EAG Kombi-Probe, Syntech, Hilversum, The Netherlands), and processed with a data acquisition controller (IDAC-4, Syntech), which was linked to a personal computer running the EAG software to analyze the recordings. The tested plant volatileextracts were applied to a piece of $8 \times 50 \mathrm{~mm}$ filter paper strip (Whatman nr 1) using $35 \mu \mathrm{L}$ of each extract. After allowing for solvent evaporation, the paper strips were placed inside a glass Pasteur pipette (Fisher Scientific, Pittsburgh, Pennsylvania, USA). A stimulus controller (CS-05, Syntech) was set to provide a continuous flow of $0.6 \mathrm{~L} \mathrm{~min}^{-1}$, and the stimuli were provide as $2 \mathrm{~s}$ puffs. At least $1 \mathrm{~min}$ was allowed between successive stimulations for antennal recovery. Ten replicates were performed per sex and volatile extract, using hexane as control.

The behavioral response of $B$. pisorum to pea volatile extracts was evaluated in a four-arm airflow olfactometer adapted from Pettersson (1970). The observation area was divided into four zones and one indifferent zone in the center was designated as the decision zone. One $B$. pisorum was enclosed in the observation arena permeated by charcoal filtered air $\left(800 \mathrm{~mL}^{-1}\right)$ coming from each of its four stretched-out corners and drawn out through a hole above its center. Olfactometric bioassays were carried out between 10:00 and 18:00 h (photophase) at $22 \pm 1{ }^{\circ} \mathrm{C}$ and 80 lux. Two lines of air coming from each stimulus treatment were connected in opposite corners of the arena; the other two lines released hexane as a control treatment (Parra et al., 2009). The chemical stimuli (odors of plant extracts) were applied onto a paper strip $(8 \mathrm{~mm} \times 60 \mathrm{~mm}$, Whatman $\mathrm{nr} 1$ filter paper) and placed into a glass tube (10.0 cm high; $1.0 \mathrm{~cm} \mathrm{ID),} \mathrm{connected} \mathrm{to} \mathrm{each} \mathrm{olfactometer}$ arm. The time spent in each arm of the olfactometer was recorded during $10 \mathrm{~min}$ with the olfactometer being rotated (90 ${ }^{\circ}$ clockwise) every minute to minimize directional bias. Five minutes before starting the experiment, the test specimen of $B$. pisorum was placed in the olfactometer for acclimation. The insects were tested only once, and 10 replicates per sex were performed for each extract using a different clean-olfactometer.

\section{Data analysis}

The spent time by insects in different zones of the olfactometer was submitted to a non-parametric oneway analysis based on ranks trough Kruskal-Wallis test, and groups were separated using the Conover-Inman test ( $\mathrm{P} \leq 0.05$ ) (Derryberry et al., 2010). An olfactometricpreference index $(\mathrm{OPI})$, where OPI $=2 \mathrm{~T} /(\mathrm{T}+\mathrm{C})(\mathrm{Kogan}$ and Goeden, 1970; Kogan, 1972), was calculated to reflect the effect of the stimulus on the behavior of the insect. The OPI values ranged from 0 to 2 , with OPI $=1$ indicating no olfactometric preference for the control or treatment odor source, OPI $>1$ indicating preference for treatment odor source, and OPI $<1$ indicating preference for control odor source. Furthermore, to ensure that insects were not biased in their preferences, a complete set of experiments for each sex was done using hexane in all arms. According to Kogan (1972) if no factor other than random distribution of the insect in the arena accounted for time-spent in each zone of the olfactometer, the mean value of OPI for all replicates control using hexane $\left(\mathrm{OPI}_{\mathrm{H}}\right)$ should be approximate 1 . These values were used to correct OPI within each series of test following an adaptation of Abbott's formula: $\mathrm{OPI}_{\mathrm{K}}=\mathrm{OPI}_{\mathrm{H}}(1+\mathrm{K})$, where $\mathrm{IPO}_{\mathrm{K}}$ is the corrected value of OPI (Kogan, 1972). Values of $\mathrm{OPI}_{\mathrm{K}}$ were analyzed with procedures describe above, with non-parametric one-way analyses based on ranks trough Kruskal-Wallis test followed by ConoverInman test $(\mathrm{P} \leq 0.05)$ (Derryberry et al., 2010). The EAG data between sexes were analyzed by $t$-test $(\mathrm{P} \leq 0.05)$, and data within a same sex were submitted to ANOVA and groups were separated by Tukey's test $(\mathrm{P} \leq 0.05)$.

\section{RESULTS AND DISCUSSION}

\section{Identification of plant volatile compounds}

The literature concerning qualitative and quantitative data of the volatile content in $P$. sativum is scarce. To our knowledge, the identification and quantification of the headspace composition of volatiles from live plants of $P$. sativum have not been carried out previously. The GC-MS analysis of plant-emitted volatiles showed qualitative and quantitative differences between analyzed phenological stages (Table 1). Terpenes were the most abundant compounds in all collections, and terpinene and $1-S$-verbenone were detecting only at flower stage at 19.92 and $2.02 \mathrm{ng} \mu \mathrm{L}^{-1}$, respectively (Table 1). Flowers emitted large amounts of all compounds, except for myrcene $(0.87$ ng $\left.\mu \mathrm{L}^{-1}\right)$ and $n$-dodecane (3.82 ng $\left.\mu \mathrm{L}^{-1}\right)$. Pea pods emitted small quantities of (Z)-2-hexen-1-ol, 2,4-hexadienal,

Table 1. Compounds identified in a headspace sample of pea (Pisum sativum) at vegetative, flower, and pod phenological stages.

\begin{tabular}{|c|c|c|c|c|c|c|}
\hline \multirow[b]{2}{*}{ Compound $^{\mathrm{a}}$} & \multirow[b]{2}{*}{ Rt } & \multicolumn{2}{|c|}{$\begin{array}{l}\text { Linear retention } \\
\text { indices }\end{array}$} & \multicolumn{3}{|c|}{$\begin{array}{c}\text { Concentration at } \\
\text { phenological stages }\end{array}$} \\
\hline & & Exp. & Lib. & Veg. & Flower & Pod \\
\hline & $\min$ & & & & $\operatorname{ng} \mu \mathrm{L}^{-1}$ & \\
\hline Hexanal $^{(1,2,3)}$ & 7.14 & 772 & 773 & 3.50 & 5.41 & nd \\
\hline (Z)-2-Hexen-1-ol ${ }^{(1,2)}$ & 10.08 & 863 & 865 & 2.03 & 6.48 & 0.51 \\
\hline 2,4-Hexadienal ${ }^{(1,2)}$ & 11.10 & 885 & 884 & 2.08 & 2.52 & 1.49 \\
\hline$\alpha$-Pinene ${ }^{(1,2,3)}$ & 13.04 & 933 & 934 & 5.42 & 9.57 & 1.37 \\
\hline Camphene $\mathrm{e}^{(1,2,3)}$ & 13.55 & 946 & 952 & 0.12 & 0.55 & nd \\
\hline$\beta$-Pinene ${ }^{(1,2,3)}$ & 14.57 & 971 & 978 & 6.78 & 11.78 & 1.66 \\
\hline Myrcene $^{(1,2)}$ & 15.21 & 986 & 986 & 3.16 & 0.87 & 0.54 \\
\hline 3-Carene ${ }^{(1,2,3)}$ & 15.84 & 1000 & 1001 & 1.42 & 3.65 & nd \\
\hline Limonene $^{(1,2)}$ & 16.56 & 1021 & 1017 & 7.11 & 5.56 & 0.07 \\
\hline Terpinene $^{(1,2)}$ & 17.05 & 1035 & 1055 & nd & 19.92 & nd \\
\hline Terpinolene $\mathrm{e}^{(1,2)}$ & 18.85 & 1084 & 1084 & 3.36 & 12.20 & nd \\
\hline 1-Methylbutyl-benzene ${ }^{(1,2,3)}$ & 19.45 & 1099 & 1082 & 2.03 & 5.00 & nd \\
\hline 1-(S)-Verbenone ${ }^{(1,2)}$ & 22.12 & 1181 & 1191 & nd & 2.02 & nd \\
\hline n-Dodecane ${ }^{(1,2,3)}$ & 22.74 & 1199 & 1199 & 2.34 & 3.82 & 6.77 \\
\hline
\end{tabular}

${ }^{\text {a Reliability of the identification is indicated by: }{ }^{1} \text { mass spectrum; }{ }^{2} \text { linear }}$ retention indices; ${ }^{3}$ commercial standard compound.

Rt. Retention time; Exp.: experimental: Lib.: library; Veg.: vegetative; nd: not detected. 
$\alpha$-pinene, $\beta$-pinene, myrcene, and limonene, except for $n$-dodecane that was the dominant compound at this stage with $6.77 \mathrm{ng} \mu \mathrm{L}^{-1}$.

The highest compound concentration was found in vegetative and flower stages, which coincides with the report of Dudareva et al. (2004). They indicated that the emission of volatiles increases when leaves are young and flowers are prepared to be pollinated. The quantitative differences in volatile compounds emitted by flowers may be especially important to attract pollinators (Custodio et al., 2006). Monoterpenes, such as myrcene and $\alpha$ - and $\beta$-pinene, have been well studied in many species of bark beetles and in their host plants. The results showed that they were attractive to Hylastes ater and Hylurgus ligniperda (Reay and Walsh, 2002). Limonene was attractive to species of the Curculionidae family, such as Hylobius pales (Siegfried, 1987) and Smicronyx fulvus (Roseland et al., 1992). According to Garcia (2010), $\alpha$ - and $\beta$-pinene, 3-carene, $(S)$-cis-verbenol, and (1S)(-)-verbenone are attractive to males and females of $H$. ligniperda (Scolitidae). It has been demonstrated that trans-2-hexenal is the most abundant compound in flower volatiles of alfalfa (Medicago sativa L.) and it may be involved in mechanisms of pest and disease resistance (Tava and Picetti, 1997).

\section{Electroantennogram (EAG) responses}

The electrophysiological response of $B$. pisorum has not been carried out previously, and these recordings from insect antennae revealed responses to chemical stimuli from its host $P$. sativum. The pea-volatiles from all phenological stages elicit a significant EAG response in both male and female, and the amplitude in response to those stimuli was in the range of 0.63 to $1.35 \mathrm{mV}$ (Figure 1). In general female showed greater EAG response than males, but this was not always significant. Opposite to our results, Adhikari et al. (2002) found higher EAG responses in males of $C$. maculatus than females toward lemongrass (Cymbopogon citratus (DC.) Stapf), neem and curry (Murraya koenigii). However, a greater respond of females of $C$. macullatus was observed when the stimulus was a seed-extract of cowpea (Vigna unguiculata (L.) Walp.) (Adhikari et al., 2002). This results could be explain by the fact of the C.macullatus lay their eggs on the external surface of a dry seed of Fabaceae species. The statistical analysis showed that pea-volatiles from vegetative and pod elicit greater response in female 1.35 and $1.10 \mathrm{mV}$ than males 1.02 and $0.63 \mathrm{mV}$, respectively (Figure 1). The EAG response to volatile extract from flower showed a not significant difference between sexes. In males the EAG response to extracts from flower and pod were $76 \%$ and $68 \%$ greater and significant than the vegetative stage, respectively. In contrast, female EAG responses between phenological stages of pea were not significant each other. This behavior may be founded on the insect female's need to find a suitable host that provides food and safety for the progeny (Paukku and Kotiaho, 2008). Our results permit to establish the olfactive perception of B. pisorum for its host, and several studies have support the hypothesis that the characteristic blend of volatile compounds produced by host plants are fundamental for species-specific attraction of herbivorous insects (Webster et al., 2010; Hare, 2011; Scala et al., 2013).

\section{Olfactometer bioassay of volatiles from $\boldsymbol{P}$. sativum}

Olfactometer bioassay showed that both male and female were attracted to pea-volatiles from vegetative, flower, and pod vegetative phenological stages. Males and females of $B$. pisorum showed significant attraction to vegetative pea-volatiles spending $60 \%$ of the bioassay time, but no significant differences were found between sexes (Figure 2). The bruchids were significantly attracted to pea-volatiles from flower (Figure 3). Similarly to peavolatiles from vegetative stage, females spent $60 \%$ of the

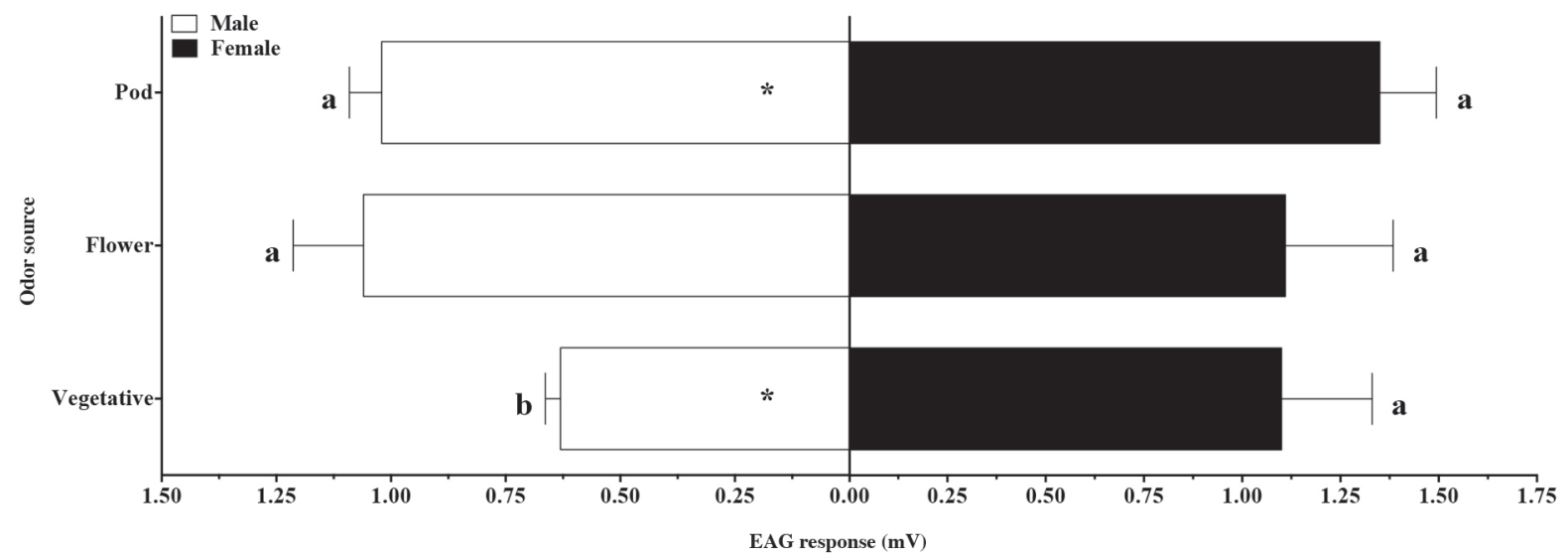

"Indicate differences between sexes, for each odor source, according to Student's $t$-test $(P<0.05)$.

Means sharing a letter, for each sex, do not differ significantly according to Tukey's test $(P<0.05)$. EAG: Electroantennography.

Figure 1. Electrophysiological response $(\mathrm{mV} \pm \mathrm{SE})$ of male and female Bruchus pisorum to Pisum sativum volatiles emitted at different phenological stages. 


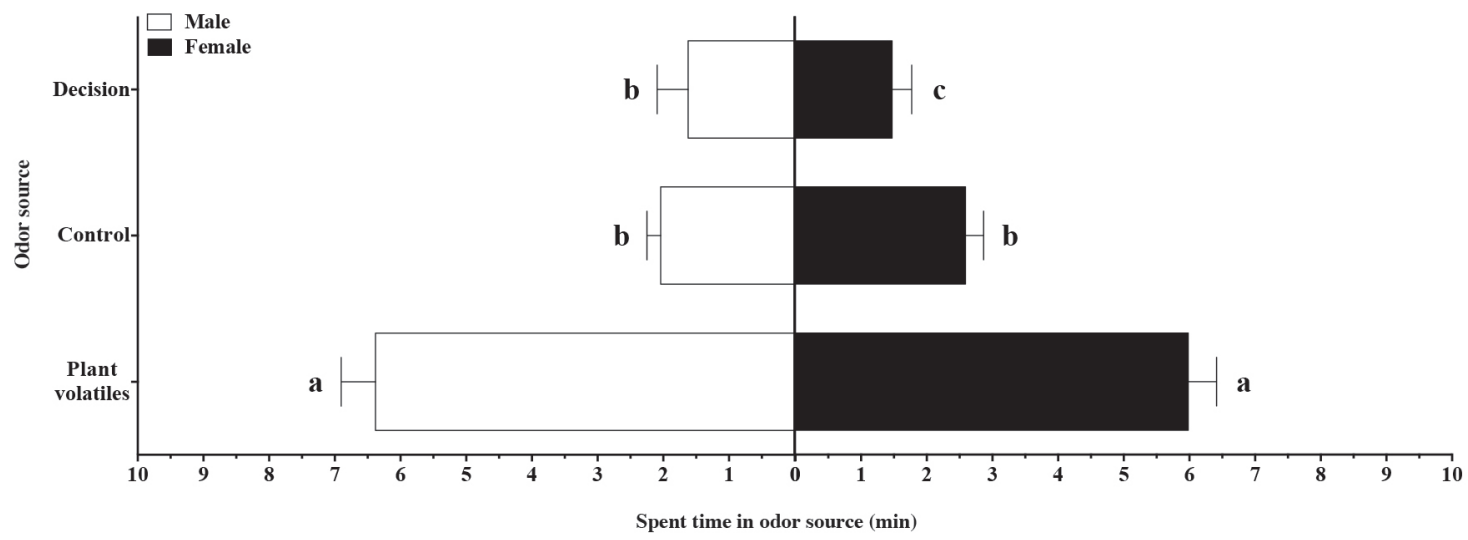

Means sharing same letter, for each sex, do not differ significantly according to Conover-Inman test $(P<0.05)$.

Figure 2. Behavioral response of Bruchus pisorum to Pisum sativum volatiles from vegetative phenological stage. Average time spent ( \pm SE) by B. pisorum in an olfactometric bioassay $(n=10)$.

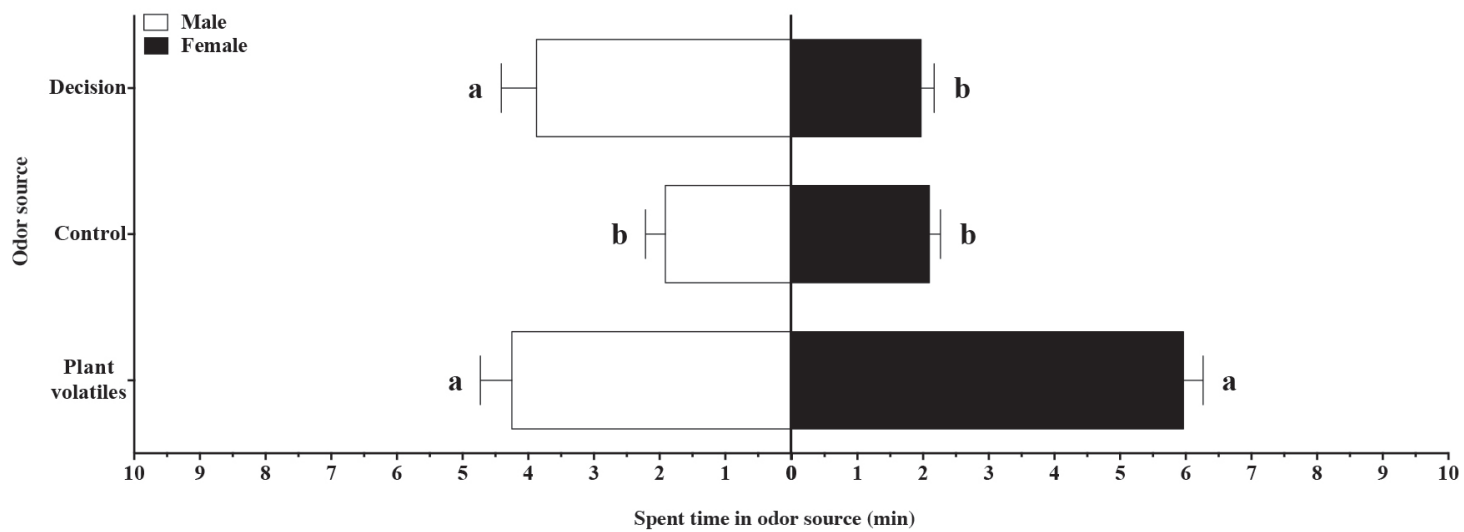

Means sharing same letter, for each sex, do not differ significantly according to Conover-Inman test $(P<0.05)$.

Figure 3. Behavioral response of Bruchus pisorum to Pisum sativum volatiles from flower phenological stage. Average time spent ( \pm SE) by $B$. pisorum in an olfactometric bioassay $(\mathbf{n}=\mathbf{1 0})$.

bioassay time visiting pea-volatiles from flower zone in the olfactometer. However, males spent $42 \%$ of the bioassay time to visit the stimuli zone (Figure 3). Pea-volatiles from pod elicit a strong significant attraction to females of B. pisorum, who spent $71 \%$ of the bioassay time visiting the stimuli zone in the olfactometer (Figure 4). On the other hand, males spent $49 \%$ to visit the zone stimulated with pea pod-volatiles (Figure 4). The attractive behavior exhibited by the insect could be explained by the presence of the terpenes such a $\alpha$ - and $\beta$-pinene; the predominant compounds in volatile extracts. That agrees with studies that have been shown how beetles are highly attracted to the monoterpenes of their host plant. For example, Tomicus piniperda is attracted to $\alpha$-pinene, terpinolene, and 3-carene (Schroeder and Weslien, 1994). According to Hofstetter et al. (2008), $\alpha$-pinene and myrcene are attractive to Dendroctonus brevicomis (Curculionidae: Scolytinae). Rodríguez et al. (2008) pointed out that limonene is considered to be toxic to insects and $\alpha$ - and $\beta$-pinene have been reported to be attractive to beetles.
$\alpha$-Pinene has a kairomonal activity for beetles, especially for bark beetles, which means that the process involves individuals from different species, and the adaptive benefit is more favorable to the organism that receives the message than to the one that emits it (Garcia, 2010). Miller and Lindgren (2000) indicated that $\alpha$-pinene and myrcene are attractive to Dendroctonus ponderosae (Coleoptera: Scolitydae) and they are used in traps. These results from olfactometric bioassays were transformed to an olfactometric-preference index (OPI), to reflect the effect of the plant-volatile stimuli on the behavior of the insect (Figure 5). In general, OPI indicated that insects have preference by pea-volatiles and females showed greater preference than males. Statistical analysis revealed difference in OPI between males and females by pea-volatiles from flower $(\mathrm{P}=0.0283)$ and pod $(\mathrm{P}=$ $0.0004)$. No discrimination between pea-volatiles from different phenological stages was found in $B$. pisorum males. According to OPI results, females showed a significant attraction to pea-volatiles from pod, and no 


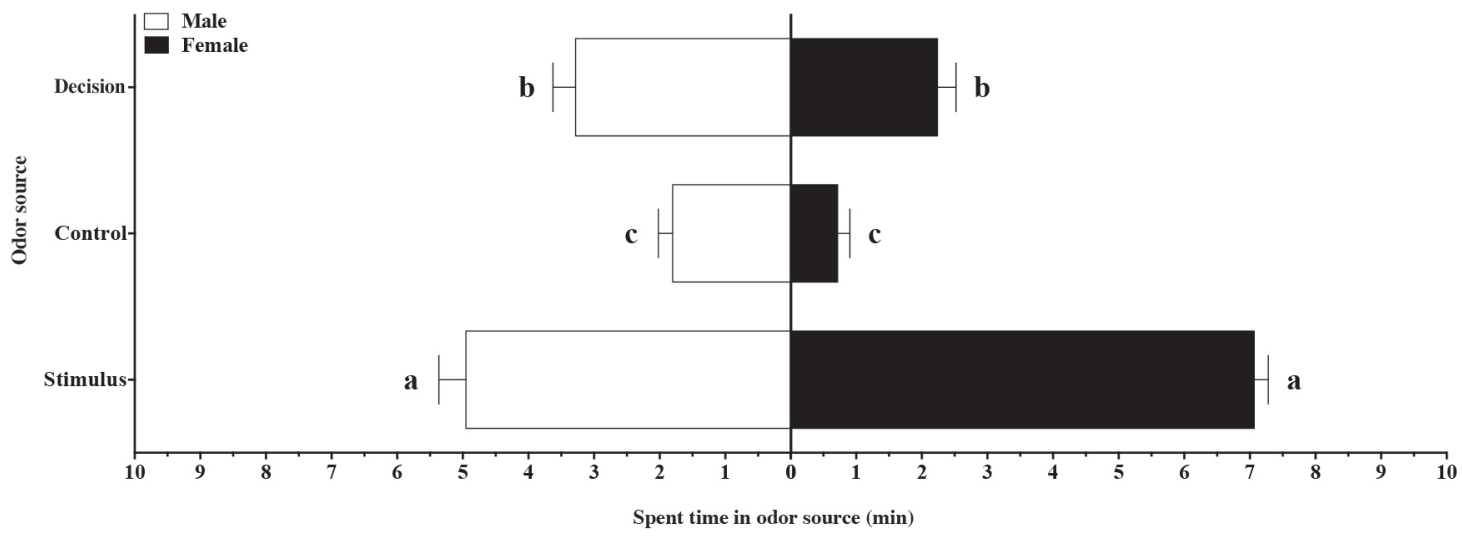

Means sharing same letter, for each sex, do not differ significantly according to Conover-Inman test $(P<0.05)$.

Figure 4. Behavioral response of Bruchus pisorum to Pisum sativum volatiles from pod phenological stage. Average time spent ( \pm SE) by $B$. pisorum in an olfactometric bioassay $(n=10)$.

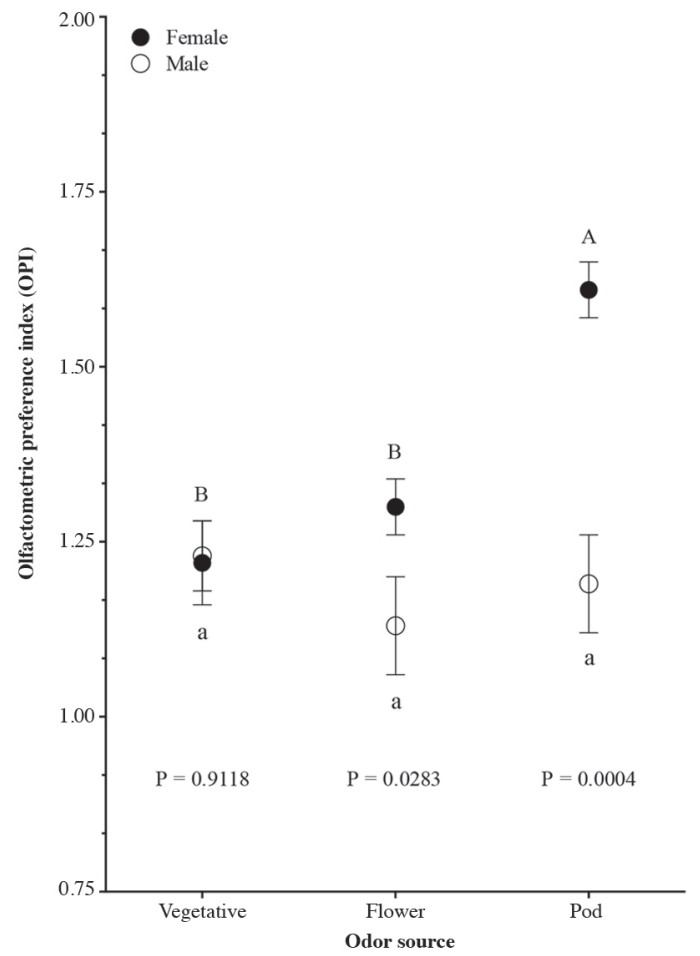

OPI $=1$ indicates no olfactometric preference for the control or treatment odor source, OPI $>1$ indicates preference for treatment odor source, and $\mathrm{OPI}<1$ indicates preference for control odor source.

Means with same letter, lower-case males and uppercase females, do not differ according to Conover-Inman test $(\mathrm{P}<0.05)$.

P-value from $U$ Mann-Whitney test $(\mathrm{P}<0.05)$ indicates differences between males and females for each phenological stage.

Figure 5. Average olfactometric preference index $(\mathrm{OPI}, \pm \mathrm{SE})$ of Bruchus pisorum in olfactometer zones in response to plant volatiles from different stages of Pisum sativum.

discrimination by pea-volatiles from vegetative or flower (Figure 5). The results may be explained as males already have spermatozoa when they emerge from the grain, therefore, they do not need pollen or any other plant part, unlike females, which need it to become sexually mature
(Medina, 1990). Nevertheless, female adults of B. pisorum did show a significant preference for the volatile extract of pea pod, this behavior maybe is due to the female's need to provide food for her offspring (Clement, 1992).

The results of the present study demonstrate that volatiles released by $P$. sativum at different phenological stages have qualitative and quantitative differences. Furthermore, these compounds elicited electrophysiological and behavioral responses from both males and females $B$. pisorum, in such a way that the female could be able to discriminate between volatiles from each phenological stage. The identification of these chemical cues from host plant of $B$. pisorum could be used to development of a monitoring system or to lure them into traps in the field. More comprehensive studies are needed to evaluate the effect of the individual compounds or combinations of them at different dose on the behavior of host selection by B. pisorum. Our study is a starting point to provide the basic and essential information to develop efficient kairomones to be used in monitoring and Integrated Pest Management (IPM) programs for pea weevil.

\section{CONCLUSIONS}

Volatiles released by Pisum sativum at different phenological stages have qualitative and quantitative differences in the mixtures of chemicals. More volatiles are releasing at flower phenological stage and most abundant chemical constituents are terpenes. Our study confirmed the antennal response and behavioral importance of the pea-volatiles from different phenological stages. Both males and females of Bruchus pisorum are attracted to pea-volatiles, but these chemical compounds elicited large electrophysiological and behavioral responses in females than males. These naturally occurring volatiles emitted by flowers and pods of pea-plants are used as innate cues in host finding by $B$. pisorum. 


\section{ACKNOWLEDGEMENT}

Financial support for this research was supplied by CONICYT (Project PBCyT PSD-05) and CORFO (Project Creación de un Centro en Control Biológico). We gratefully acknowledge to Marcos Gerding and Juan Tay, for bringing the insects and plants used in the experiments.

\section{LITERATURE CITED}

Adhikari, A., P. Paranagama, K. Abeywickrama, and K. Premarathne. 2002. Behavioural studies of cowpea seed bruchid, Callosobruchus maculatus (F.) against volatile leaf extracts of lemongrass, neem and curry leaf. Tropical Agricultural Research 14:138-147.

Agelopoulos, N., A. Hooper, S. Maniar, J. Pickett, and L. Wadhams. 1999. A novel approach for isolation of volatile chemicals released by individual leaves of a plant in situ. Journal of Chemical Ecology 25:1411-1425.

Annis, B., and L. O'Keeffe. 1987. Influence of pea genotype on parasitization of the pea weevil, Bruchus pisorum (Coleoptera: Bruchidae) by Eupteromalus leguminis (Hymenoptera: Pteromalidae). Environmental Entomology 16:653-655.

Bleeker, P., P. Diergaarde, K. Ament, J. Guerra, M. Weidner, S. Schutz, et al. 2009. The role of specific tomato volatiles in tomatowhitefly interaction. Plant Physiology 151:925-935.

Bruce, T.J.A., J.L. Martin, L.E. Smart, and J.A. Pickett. 2011. Development of semiochemical attractants for monitoring bean seed beetle, Bruchus rufimanus. Pest Management Science 67:1303-1308.

Bruce, T.J., and J.A. Pickett. 2011. Perception of plant volatile blends by herbivorous insects - finding the right mix. Phytochemistry 72:1605-1611.

Bruce, T.J.A., L.J. Wadhams, and C.M. Woodcock. 2005. Insect host location: a volatile situation. Trends in Plant Science 10:269-274.

Carey, A.F., and J.R. Carlson. 2011. Insect olfaction from model systems to disease control. Proceedings of the National Academy of Sciences of the United States of America 108:12987-12995.

Casado, D., C. Cemeno, J. Avilla, and M. Riba. 2006. Daynight and phenological variation of apple tree volatiles and electroantennogram responses in Cydia pomonella (Lepidoptera: Tortricidae). Environmental Entomology 35:258-267.

Clement, S. 1992. On the function of pea flower feeding by Bruchus pisorum. Entomologia Experimentalis et Applicata 63:115-121.

Clement, S.L., K.E. McPhee, L.R. Elberson, and M.A. Evans. 2009. Pea weevil, Bruchus pisorum L. (Coleoptera: Bruchidae), resistance in Pisum sativum $\times$ Pisum fulvum interspecific crosses. Plant Breeding 128:478-485.

Custodio, L., H. Serra, J.M.F. Nogueira, S. Goncalves, and A. Romano. 2006. Analysis of the volatiles emitted by whole flowers and isolated flower organs of the carob tree using HS-SPME-GC/ MS. Journal of Chemical Ecology 32:929-942.

Derryberry, D.R., S.B. Schou, and W.J. Conover. 2010. Teaching rank-based tests by emphasizing structural similarities to corresponding parametric tests. Journal of Statistics Education 18:1-19.

Dudareva, N., F. Negre, D.A. Nagegowda, and I. Orlova. 2006. Plant volatiles: Recent advances and future perspectives. Plant Sciences 25:417-440.

Dudareva, N., E. Pichersky, and J. Gershenzon. 2004. Biochemistry of plant volatiles. Plant Physiology 135:1893-1902.

El-Sayed, A.M. 2014. The pherobase: Database of pheromones and semiochemicals. Available at http://www.pherobase.com (accessed May 2012).

Garcia, M. 2010. Rol de los compuestos volátiles de Pinus radiata (D. Don) en la selección de hospedero por Hylurgus ligniperda (Fabricius) (Coleoptera: Scolytidae). Universidad de Concepción, Concepción, Chile.
Gerding, M., J. Tay, y M. Paredes. 1987. Incidencia de Bruchus pisorum (Coleoptera: Bruchidae) en arveja, según época de siembra. Agricultura Técnica 47:160-162.

Hansson, B.S., and M.C. Stensmyr. 2011. Evolution of insect olfaction. Neuron 72:698-711.

Hardie, D., G. Baker, and D. Marshall. 1995. Field screening of Pisum accessions to evaluate their susceptibility to the pea weevil (Coleoptera: Bruchidae). Euphytica 84:155-161.

Hardie, D., and S. Clement. 2001. Development of bioassays to evaluate wild pea germplasm for resistance to pea weevil (Coleoptera: Bruchidae). Crop Protection 20:517-522.

Hare, J.D. 2011. Ecological role of volatiles produced by plants in response to damage by herbivorous insects. Annual Review of Entomology 56:161-180.

Hofstetter, R.W., Z. Chen, M.L. Gaylord, J.D. McMillin, and M.R Wagner. 2008. Synergistic effects of alpha-pinene and exobrevicomin on pine bark beetles and associated insects in Arizona. Journal of Applied Entomology 132:387-397.

Holopainen, J. 2004. Multiple functions of inducible plant volatiles. Trends in Plant Science 9:529-533.

Horne, J., and P. Bailey. 1991. Bruchus pisorum L. (Coleoptera, Bruchidae) control by a knockdown pyrethroid in field peas. Crop Protection 10:53-56

Kogan, M. 1972. Feeding and nutrition of insects associated with soybeans. 2. Soybean resistance and host preferences of the Mexican bean beetle, Epilachna varivestis. Annals of the Entomological Society of America 65:675-683.

Kogan, M., and R. Goeden. 1970. The host-plant range of Lema trilineata daturaphila (Coleoptera: Chrysomelidae). Annals of the Entomological Society of America 63:1175-1180.

Kundsen, J., L. Tollsten, and G. Bergström. 1993. Floral scent: a checklist of volatile compounds isolated by head-space techniques. Phytochemistry 33:253-280.

Medina, V. 1990. Modificación del comportamiento y disminución del daño de Bruchus pisorum L. con cultivos múltiples y extractos vegetales. Universidad de Concepción, Chillán, Chile.

Michael, P., D. Hardie, and P. Mangano. 1993. Insect and mite control. p. 65-77. In Pritchard, I., J. Carpenter, and W. Anderson (eds.) Growing field peas. Western Australian Department of Agriculture, Western Australia, Perth, Australia.

Miller, D., and S. Lindgren. 2000. Comparison of a-pinene and myrcene on attraction of mountain pine beetle, Dendroctonus ponderosae (Coleoptera: Scolytidae) to pheromones in stands of western white pine. Journal of the Entomological Society of British Columbia 97:41-45.

NIST. 2014. Base de Datos de Referencia Estándar del NIST Número 69. Libro del Web de Química del NIST. National Institute of Standards and Technology (NIST), Gaithersburg, Maryland, USA. Available at http://webbook.nist.gov/chemistry (accessed June 2012).

Pajni, H.R. 1986. Ecological status of host range and polymorphism in Bruchidae. Proceedings of the Fourth International Working Conference on Stored Product Protection, Tel Aviv, Israel. 21-26 September 1986. CABI, Wallingford, UK.

Palma, R., A. Mutis, L. Manosalva, R. Ceballos, and A. Quiroz. 2012 Behavioral and electrophysiological responses of Hylastinus obscurus to volatiles released from the roots of Trifolium pratense L. Journal of Soil Science and Plant Nutrition 12:183-193.

Paranagama, P., A. Adhikari, K. Abeywickrama, and K. Bandara. 2003. Evaluation of volatile constituent of Neem (Azadirachta indica A. Juss.) leaf extract against Callosobruchus maculatus (F.) Journal of the National Science Foundation of Sri Lanka 31:445-458.

Parra, L., A. Mutis, R. Ceballos, M. Lizama, F. Pardo, F. Perich, et al. 2009. Volatiles from Vaccinium corymbosum were attractive to Aegorhinus superciliosus (Coleoptera: Curculionidae) in an olfactometric bioassay. Environmental Entomology 38:781-789.

Paukku, S., and J.S. Kotiaho. 2008. Female oviposition decisions and their impact on progeny life-history traits. Journal of Insect Behavior 21:505-520 
Pesho, G., F. Muehlbauer, and W. Harberts. 1977. Resistance of pea introductions to the pea weevil. Journal of Economic Entomology 70:30-33.

Pettersson, J. 1970. An aphid sex attractant. I. Biological Studies. Entomologia Scandinavica 1:63-73.

Reay, S., and P. Walsh. 2002. Relative attractiveness of some volatiles to the introduced pine bark beetles, Hylastes ater and Hylurgus ligniperda (Curculionidae: Scolytidae). New Zealand Entomologist 25:51-56.

Rodríguez, D., J.Cure, y F. Cantor. 2008. Respuesta de Hypothenemus hampei Ferrari (Coleoptera: Curculionidae: Scolytinae) a estímulos olfativos: estado actual y perspectivas. Revista de la Facultad de Ciencias Básicas 41:24-31.

Roseland, C., M. Bates, R. Carlson, and C. Oseto. 1992. Discrimination of sunflower volatiles by the red sunflower seed weevil. Entomologia Experimentalis et Applicata 62:99-106.

Sato, K., and K. Touhara. 2009. Insect olfaction: receptors, signal transduction, and behavior. Results and Problems in Cell Differentiation 47:121-138.
Scala, A., S. Allmann, R. Mirabella, M.A. Haring, and R.C. Schuurink. 2013. Green leaf volatiles: A plant's multifunctional weapon against herbivores and pathogens. International Journal of Molecular Sciences 14:17781-17811.

Schroeder, L.M., and J. Weslien. 1994. Reduced offspring production in bark beetle Tomicus piniperda in pine bolts baited with ethanol and alpha-pinene, which attract antagonistic insects. Journal of Chemical Ecology 20:1429-1444.

Siegfried, B. 1987. In-flight responses of the pales weevil, Hylobius pales (Coleoptera: Curculionidae) to monoterpene constituents of southern pine gum turpentine. Florida Entomologist 70:97-102.

Tava, A., and L. Picetti. 1997. Volatiles from Medicago sativa complex flowers. Phytochemistry 45:1145-1148.

Webster, B., T. Bruce, J. Pickett, and J. Hardie. 2010. Volatiles functioning as host cues in a blend become nonhost cues when presented alone to the black bean aphid. Animal Behaviour 79:451-457. 